\title{
Facilitation of two-way avoidance of the guinea pig following intrahippocampal injections of procaine hydrochloride*
}

\author{
CHARLES S. WEISS $\div$ and DAVID R. HERTZLER \\ State University of New York, College at Oswego, Oswego, New York 13126
}

\begin{abstract}
Guinea pigs received intrahippocampal injections of procaine hydrochloride ( $\mathrm{P}-\mathrm{HCl})$ or isotonic saline and were conditioned in a two-way avoidance situation. Animals receiving $\mathrm{P}-\mathrm{HCl}$ acquired the learning criterion in significantly fewer trials than those receiving isotonic saline. Following acquisition, a shifting of drug conditions resulted in no change in the rate of avoidance responses but in altered rates of intertrial crossings. Animals shifted from P- $\mathrm{HCl}$ to isotonic saline decreased intertrial crossings, while those shifted from saline to $\mathrm{P}-\mathrm{HCl}$ showed increased intertrial activity compared to animals that continued to receive the initial treatment.
\end{abstract}

The guinea pig has been shown to perform poorly in two-way active avoidance tasks (Evonic \& Brimer, 1967; Ireland, Hayes, \& Schaub, 1969). Several investigations have been concerned with various physiological manipulations on the two-way avoidance responses of the guinea pig; these procedures include lesions in the central visual system (Dyer, 1971), septal area (Lown, Hayes, \& Schaub, 1969), and hippocampus (Ireland et al, 1969). Such physiological manipulations have resulted in facilitated acquisition of the avoidance task. Often this enhanced avoidance performance is accompanied by increases in the number of intertrial crossings and changes in the relationship between intertrial activity and number of avoidances. The present experiment was designed to examine the effects of transient chemical lesions of the hippocampus (produced by intrahippocampal injection of procaine hydrochloride; $\mathrm{P}-\mathrm{HCl}$ ) on the acquisition and performance of a two-way active avoidance task by the guinea pig. The state-dependent nature of avoidance performance, intertrial crossings, and drug condition (lesion presence or absence) was determined following acquisition. If a state-dependent relationship exists, then a shift from $\mathrm{P}-\mathrm{HCl}$ to isotonic saline injection should decrease both the number of avoidances and intertrial crossings. A shift from saline to $\mathrm{P} . \mathrm{HCl}$ should result in increases in these measures.

\section{METHOD}

\section{Subjects}

Thirteen male and one female 60 -day-old naive guinea pigs (Cavia porcellus), weighing $278-463 \mathrm{~g}$ were purchased from Chordata Corporation, Ontario. New York. Subjects were

*This article is based on a thesis submitted to the Department of Psychology. 'State University of New York, College at Oswego, in partial fulfillment of the requirements for the MA degree by C.S.W. under the supervision of D.R.H. Portions of this paper were presented at the Annual Meeting of the Midwestern Psychological Association. Cleveland. 1972.

$\div$ Now at the Department of Psychology. Ohio University. A thens, Ohio 45701. Requests for reprints should be sent there. housed individually and maintained ad lib with Agway guinea pig chow and water plus a daily supplement of lettuce.

\section{Apparatus}

Two-way avoidance conditioning was conducted in a tilt cage $(42.3 \times 17.8 \times 19.1 \mathrm{~cm})$, in which one side was elevated $2.5 \mathrm{~cm}$ above the other such that the animal had to step up or step down when moving from one end of the apparatus to the other. Microswitches located at the ends of the tilt cage indicated any crossings that were made by the animals. The conditioned stimulus (CS) was a $1,000-\mathrm{Hz}$ pure tone of $83 \mathrm{~dB}$ (SPL), as measured from the approximate position of the $S$ during conditioning. The unconditioned stimulus (UCS) was a $1.00-\mathrm{mA}$ ac electric shock. produced by a Lehigh Valley Electronics No. 1643 shocker on each side of the tilt cage. Shocks were delivered through a grid floor construrcted of $0.64-\mathrm{cm}$ brass rods spaced $1.2 \mathrm{~cm}$ apart. The tilt cage was housed in an Industrial Acoustics Corporation double-wall acoustic chamber with illumination provided by four $150-\mathrm{W}$ bulbs. Automated programming and recording apparatus was located outside the acoustic chamber.

\section{Procedure}

Cannulae (David Kopf Instruments, Model 201) were precut to a length of $5.00 \mathrm{~mm}$ and filled with isotonic saline to prevent pressure differences between brain and interior of the cannula (Wilsoncroft \& Law, 1967). Bilateral cannulae were stereotaxically implanted under Nembutal anesthesia $(35 \mathrm{mg} / \mathrm{kg})$ into the dorsal hippocampus (coordinates: $A-P+5.0, L \pm 4.4$, $\mathrm{V} 4.5 \mathrm{~mm}$ from the skull surface using $5-\mathrm{mm}$ incisor bar elevation; Luparello, 1967) and fixed to the skull with jewelers screws and dental acrylic. The surgical field was dusted with acromycin powder, and $S$ s returned to their home cage for a minimum 5-day recovery period. The animals were then divided randomly into the experimental (EX) and surgical control (SC) groups. On Days 1-6, Group EX received a 6-microliter injection of $50 \mathrm{mg} / \mathrm{ml}$ procaine hydrochloride $(\mathrm{P}-\mathrm{HCl} ;$ Sigma Chemical Corporation) followed by a 2 -microliter injection of isotonic saline into each cannula $10 \mathrm{~min}$ prior to avoidance conditioning. Group SC received an 8 -microliter injection of isotonic saline into each cannula $10 \mathrm{~min}$ before avoidance conditioning.

Between Days 6 and 7 , one $S$ in each group dislodged cannulae in the home cage, consequently requiring their elimination from Days 7 and 8 of the study. On Days 7 and 8 , each initial treatment group was divided into two drug shift conditions. One-half of each group continued to receive the drug that was injected on Days 1-6. The other half of each group received injections of the opposite drug. Each of the daily sessions consisted of 25 trials of two-way avoidance conditioning 


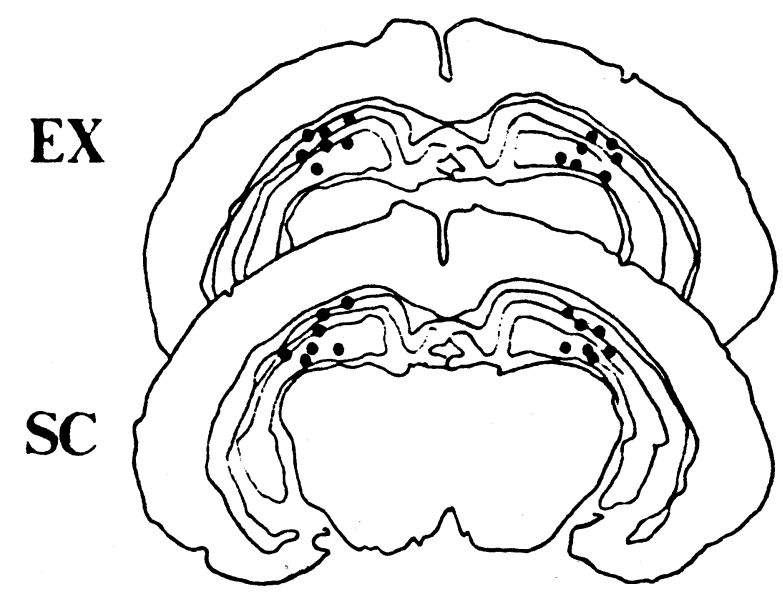

Fig. 1. Location of cannula tips (black dots) for animals in Group EX (top) and Group SC (bottom) traced on $5.0-\mathrm{mm}$ anterior section from Luparello (1967) atlas.

(150 trials acquisition; 6 days). The CS duration was $15 \mathrm{sec}$, with LCS being presented $10 \mathrm{sec}$ after CS onset. Shock then continued for $5 \mathrm{sec}$, or until an escape response was made. An avoidance response occurred when the animal moved from one end of the tilt cage to the other during the 10-sec CS-LCS interval. When this response occurred. the CS was stopped and UCS not presented. A randomized 60-sec intertrial interval and learning criterion of 9 avoidances in 10 trials was used.

\section{RESULTS}

\section{Histological}

Animals were sacrificed with Nembutal overdose and were perfused with isotonic saline followed by $10 \%$ Formalin. The brains were then extracted and stored in $10 \%$ Formalin for at least 10 days. Frozen serial sections, 50 microns thick, through the cannulated area were mounted and stained with cresyl violet. Analysis of the cannulated site showed that cannula tip locus was confined to the dorsal hippocampus approximately $4.5 \mathrm{~mm}$ lateral to midline. Figure 1 shows the location of cannula tips for all animals.

\section{Behavioral}

Analysis of variance performed on the number of trials to learning criterion ( 9 avoidances in 10 trials) indicated that those animals receiving intrahippocampal injections of $\mathrm{P}-\mathrm{HCl}$ required significantly fewer trials to criterion than those receiving saline $(\mathrm{F}=7.39, \mathrm{df}=1 / 12$, $\mathrm{p}<.025)$. Figure 2 shows the number of trials to learning criterion for Ss in both groups. Note in Fig. 2 that, after 60 trials, five animals in Group EX achieved criterion while no Ss in Group SC did so. Following 150 trials of acquisition training, all animals in Group EX reached criterion while two in Group SC did not.

No reliable differences were found between groups on the number of trials to first avoidance response $(\mathrm{F}=$ 1.70. $\mathrm{df}=1 / 12, \mathrm{p}>.20)$, the number of intertrial crossings $(F=3.93, \mathrm{df}=1 / 12, \mathrm{p}>.20)$, crossings over days $(F<1)$, or Days by Groups interaction $(F=1.70$. $\mathrm{df}=1 / 12, \mathrm{p}>.20)$. Pearson product moment correlation computed between avoidances and intertrial crossings was significant for Group SC $(\mathrm{r}=+.61, \mathrm{df}=5$. $\mathrm{p}<.05)$ and showed a positive but nonsignificant relationship for Group EX $(\mathrm{r}=+.50, \mathrm{df}=5, \mathrm{p}<.10)$.

The effects of shifting treatment conditions were assessed by subtracting scores on Days 5 and 6 from scores on Days 7 and 8 for avoidances and intertrial crossings. This procedure indicates the net change and direction of responding following the drug shift. A two-factor analysis of variance (Initial Drug by Shifted-Not Shifted) was performed for both avoidances and intertrial crossings. No difference in avoidance responding was found for initial drug treatment $(F<1)$, drug shift treatment $(F<1)$, or the interaction of Initial by Shifted Treatments $(F=2.47, \mathrm{df}=1 / 8, \mathrm{p}>.20)$. The number of intertrial crossings was not different as a function of initial drug received $(F<1)$ or shift treatment $(F=1.54, \mathrm{df}=1 / 8, \mathrm{p}>.20)$, while the Initial by Shift interaction was significant $(F=22.0, \mathrm{df}=1 / 8$. $\mathrm{p}<.005)$. Individual comparisons indicated that those Ss that were shifted from $\mathrm{P} \cdot \mathrm{HCl}$ to saline displayed significantly less intertrial crossings $(F=6.23, d f=1 / 8$, $\mathrm{p}<.05)$ than those who continued to receive $\mathrm{P} \cdot \mathrm{HCl}$. Those animals that initially received saline and were shifted to $\mathrm{P} \cdot \mathrm{HCl}$ showed a significant increase in intertrial crossings $(F=18.11, \mathrm{df}=1 / 8, \mathrm{p}<.005)$ compared to those that were not shifted from saline. Figure 3 shows the relative change in avoidances and intertrial crossings following a shift of drug conditions (on Days 7 and 8 ) as indicated by a ratio. This ratio was computed for each initial drug group by dividing the responses of animals that had drugs shifted by the responses of those Ss that did not have drugs shifted. A response ratio of one (1) indicates no change in responding after drug shift. Ratios greater or less than one denote increases or decreases, respectively, in these measures. It can be seen in Fig. 3 that after acquisition the drug shift results in nonsignificant changes in avoidance rate. Animals that initially received saline and were then shifted to $\mathrm{P}-\mathrm{HCl}$ show significant (over

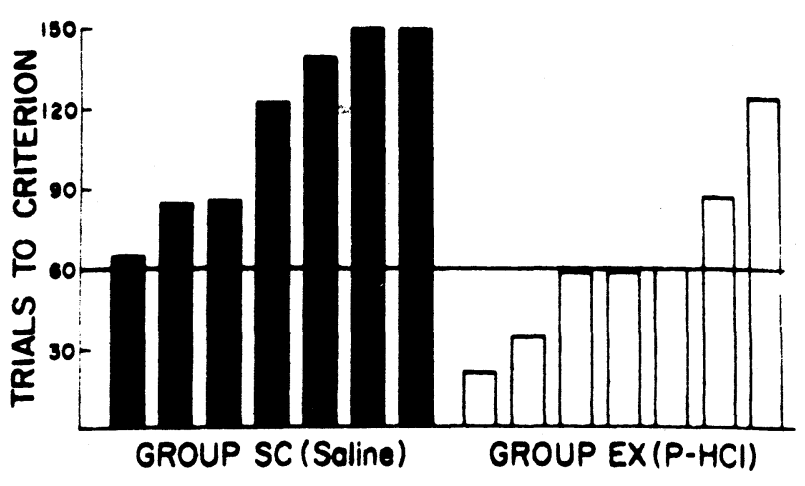

Fig. 2. Number of trials to learning criterion ( 9 avoidances in 10 trials) for Ss in both groups. Note that in Group SC two animals did not reach criterion within 150 trials. 
fourfold) increases in intertrial crossings. Those Ss that first had $\mathrm{P}-\mathrm{HCl}$ and were then shifted to saline show a significant $(50 \%)$ reduction in intertrial activity. After acquisition, shift control animals that always received $\mathrm{P} \cdot \mathrm{HCl}$ exhibited significantly more intertrial crossings than those shift controls that always received saline $(\mathrm{F}=$ $10.45, \mathrm{df}=1 / 8, \mathrm{p}<.025)$. These data demonstrate that following 150 trials (acquisition), a state-dependent relationship exists between intertrial crossings and drug condition (presence or absence of chemical lesion), whereas this relationship was not found for avoidance responding. Avoidance performance at asymptotic acquisition levels appears to be independent of intertrial crossings.

\section{DISCUSSION}

The results of this investigation indicated that acquisition of avoidance behavior for the guinea pig was facilitated by a chemically produced, transient lesion in the dorsal hippocampus. Those animals that received $\mathrm{P}-\mathrm{HCl}$ injections required significantly fewer trials to achieve learning criterion than saline control animals. This result is in agreement with studies concerning the effects of hippocampal lesions and avoidance behavior for guinea pig (Ireland et al, 1969), rat (Olton \& Isaacson, 1968), and rabbit (Papesdorf \& Woodruff, 1970). The intertrial crossing data is in accord with the results of Isaacson, Douglas, and Moore (1961), in which both surgical control and experimental groups had an elevated rate of intertrial crossings but were not different from each other. Correlations of avoidances and intertrial crossings during acquisition indicate a trend in which animals having many intertrial crossings tend to have many avoidances. Ireland et al (1969) reported that there was no current data to determine the nature of this correlation (causative or coincidental) between intertrial activity levels and avoidance rate. The present investigation shows that after acquisition a state-dependent relation exists between $\mathrm{P}-\mathrm{HCl}$ injection (lesion presence) and intertrial crossings, such that Ss having $\mathrm{P}-\mathrm{HCl}$ injections showed elevated rates of intertrial responding. This type of state-dependent relation was not found for avoidance responding. This implies that after acquisition has occurred, a high avoidance rate is maintained even after a shift from $\mathrm{P} \cdot \mathrm{HCl}$ to saline, although the intertrial activity is reduced. Conversely, following acquisition, no change in avoidance rate is shown when animals are shifted from saline to $\mathrm{P} \cdot \mathrm{HCl}$, but an increase in intertrial crossings is evident. These results demonstrate that following the acquisition phase of conditioning, avoidance performance is maintained at a high level and does not occur as a function of intertrial activity, but rather these

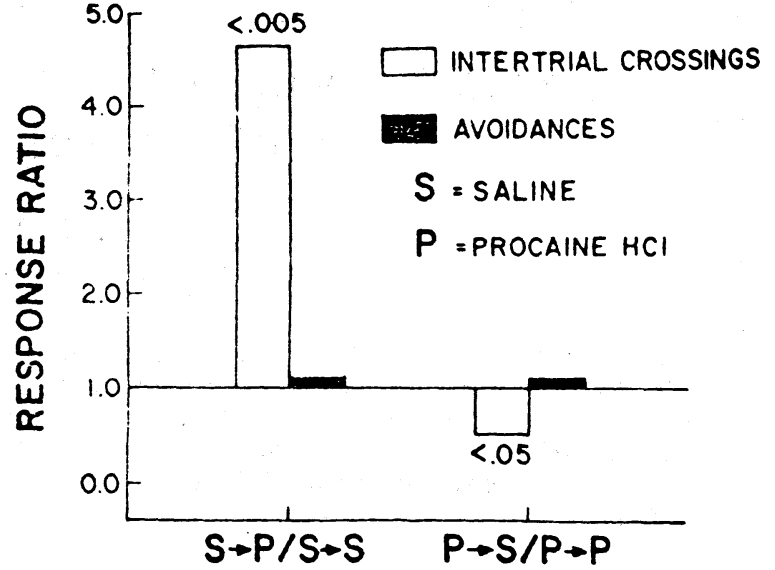

Fig. 3. The relative change of avoidances and intertrial crossings after drug shift. A response ratio indicating changes in performance was computed by dividing the mean number of responses on Days 7 and 8 for the shifted group by the responses of the group that was not shifted. (See text for explanation.)

two variables coincide in time. Hippocampal lesions appear to be facilitory only for acquisition of the task, since changes from lesion presence $(\mathrm{P}-\mathrm{HCl})$ to lesion absence (saline) cause no deficit in avoidance performance after acquisition.

\section{REFERENCES}

Dyer, R. S. Influences of the visual system upon two-way avoidance learning in the guinea pig. Journal of Comparative \& Physiological Psychology, 1971, 76, 434-440.

Evonic, I. N., \& Brimer, C. J. Effect of variable temporal parameters in avoidance conditioning of the guinea pig. Journal of Comparative \& Physiological Psychology, 1967, 63, $536-538$.

Ireland, L. C., Hayes, W. N., \& Schaub, R. E. The effects of bilateral hippocampal lesions on two-way active avoidance in the guinea pig. Psychonomic Science, 1969, 14, 249-250.

Isaacson, R. L., Douglas, R. J., \& Moore, R. Y. The effect of radical hippocampal ablation on acquisition of avoidance response. Journal of Comparative \& Physiological Psychology, $1961,54,625-628$.

Lown, B. A., Hayes, W. N., \& Schaub, R. E. The effects of bilateral septal lesions on two-way active avoidance in the guinea pig. Psychonomic Science, 1969, 16, 13-14.

Luparello, T. J. Stereotaxic atlas of the forebrain of the guinea pig. Baltimore: Williams \& Wilkens, 1967.

Olton. D. S., \& Isaacson. R. L. Hippocampal lesions and active avoidance. Physiology \& Behavior, 1968, 3, 719-724.

Papesdorf, J., \& Woodruff, M. Effects of bilateral hippocampectomy on the rabbit's acquisition of shuttle-box and passive avoidance responses. Journal of Comparative \& Physiological Psychology, 1970, 73, 486-489.

Wilsoncroft. W. E., \& Law, O. T. Laboratory manual for physiological psychology. Goleta. California: Psychonomic Press, 1967.

(Received for publication May 7, 1973; revision received June 4. 1973; accepted June 18, 1973.) 